\title{
Computational simulation of the effect of crystallization inhibitors on salt transport and crystallization in porous materials
}

\author{
J. Kelnar, J. Maděra \& R. Černý \\ Department of Building Materials, Faculty of Civil Engineering, \\ Czech Technical University in Prague, Czech Republic
}

\begin{abstract}
Computational simulation of salt transport and crystallization in limestone depending on the presence of crystallization inhibitor in the dissolved salt is presented. The diffusion-advection model is used for the basic description of coupled water and salt transport, taking into account both water movement due to the moisture gradient and diffusion and dispersion effects within the liquid phase due to the concentration gradient. Salt crystallization in the porous body is modelled using an equilibrium model, taking into account the effect of crystallization inhibition. The effect of salt bonding on the pore walls is taken into account as well. The results of numerical simulations using a well calibrated computational model give evidence that in the analyzed case the use of crystallization inhibitors leads to the slowing down of both water and salt transport.
\end{abstract}

Keywords: salt, moisture, transport, crystallization, computer simulation.

\section{Introduction}

The mathematical analysis of experimentally determined salt concentration profiles depends on the assumed mode of salt transport in the porous material. If purely diffusion transport is assumed, common methods for solving the inverse problems for parabolic equations can be used. The simplest method makes the assumption that the diffusion coefficient is constant, the domain under solution is semi-infinite, and the boundary condition on the remaining side of a 
one-dimensional arrangement is Dirichlet type. The diffusion coefficient can be identified using the simple analytical solution of the parabolic problem with error function (e.g. [1]).

The dependence of the diffusion coefficient on salt concentration can be found if some more sophisticated methods for the analysis of measured salt profiles are used. One of the methods that can be potentially used to determine concentration dependent salt diffusion coefficients in an analogous way as moisture diffusivity or thermal conductivity is a classical Boltzmann-Matano analysis [2].

In this paper, the diffusion-advection mechanism of salt solution transport (see, e.g., [3, 4]) is adopted, taking into account the influence of moisture flow on salt transport. The original model [3] is subject of some modifications tending to the improvement of model capabilities, particularly concerning the description of drying processes.

\section{Computational model}

In the diffusion-advection model of coupled water and salt transport described in $[3,4]$, the salt mass balance is expressed as

$$
\frac{\partial\left(w C_{f}\right)}{\partial t}=\operatorname{div}\left(w D \operatorname{grad} C_{f}\right)-\operatorname{div}\left(C_{f} \vec{v}\right)-\frac{\partial C_{b}}{\partial t},
$$

where $C_{f}$ is the concentration of free salts in water $\left[\mathrm{kg} / \mathrm{m}^{3}\right], C_{b}$ the concentration of bonded salts in the whole porous body, $\left[\mathrm{kg} / \mathrm{m}^{3}\right], D$ the salt diffusion coefficient, $\left[\mathrm{m}^{2} / \mathrm{s}\right], \vec{v}$ the Darcy's velocity $[\mathrm{m} / \mathrm{s}]$, and $\mathrm{w}$ the volumetric moisture content $\left[\mathrm{m}^{3} / \mathrm{m}^{3}\right]$.

The water mass balance is expressed in the following way

$$
\frac{\partial w}{\partial t}=\operatorname{div}(\kappa \operatorname{grad} w)
$$

where $\kappa$ is the moisture diffusivity $\left[\mathrm{m}^{2} / \mathrm{s}\right]$.

Expressing Darcy's velocity in terms of moisture diffusivity,

$$
\vec{v}=-\kappa \operatorname{grad} w,
$$

the salt solution transport can be described by a system of two parabolic partially coupled differential equations with two principal material parameters, $D$ and $\kappa$, and three input variables, $C_{f}, C_{b}, w$ that must be determined experimentally.

In this paper, in addition to the effects taken into account in the original model, salt crystallization and water vapor transport are introduced as well, in order to facilitate modeling of drying experiments. The modified mathematical model can be then formulated as follows: 


$$
\begin{gathered}
\frac{\partial\left(w C_{f}\right)}{\partial t} H\left(C_{f, s a t}-C_{f}\right)=\frac{\partial}{\partial x}\left(w D \frac{\partial C_{f}}{\partial x}\right)+\frac{\partial}{\partial x}\left(C_{f} \kappa \frac{\partial w}{\partial x}\right)-\frac{\partial C_{b}}{\partial t}-\frac{\partial C_{c}}{\partial t} \\
\frac{\partial C_{c}}{\partial t}=\frac{\partial\left[w\left(C_{f}-C_{f, s a t}\right)\right]}{\partial t} H\left(C_{f}-C_{f, s a t}\right) \\
\frac{\partial w}{\partial t}=\frac{\partial}{\partial x}\left(\kappa \frac{\partial w}{\partial x}\right)+\frac{\partial}{\partial x}\left(\frac{\delta}{\rho_{w}} \frac{\partial p_{v}}{\partial x}\right)
\end{gathered}
$$

where $C_{c}$ is the amount of crystallized salt (in $\mathrm{kg} / \mathrm{m}^{3}$ of the sample), $C_{f, s a t}$ is the saturated free salt concentration (in $\mathrm{kg} / \mathrm{m}^{3}$ of the solution), $\mathrm{H}$ is the Heaviside step unit function, $\mathrm{H}(\mathrm{x} .0)=1, \mathrm{H}(\mathrm{x}<0)=0, \delta$ the water vapor diffusion permeability (in s), $p_{v}$ the partial pressure of water vapor $(\mathrm{Pa})$, and $\rho_{w}$ the density of water (in $\left.\mathrm{kg} / \mathrm{m}^{3}\right)$.

The computational implementation of the mathematical model of coupled moisture and salt transport (4)-(6) was then performed using the Galerkin finite element method, and a computer code was written.

\section{Simulated drying experiment and the parameter identification process}

In the drying experiment (performed by L. Pel at TU Eindhoven, see [5] for details), limestone samples were saturated first by $3 \mathrm{M}-\mathrm{NaCl}$ solution either without or with $0.001 \mathrm{M} \mathrm{Na}_{4} \mathrm{Fe}(\mathrm{CN})_{6} \cdot 10 \mathrm{H}_{2} \mathrm{O}$ as crystallization inhibitor. Then the drying process was started in an environment with a relative humidity close to $0 \%$. Moisture and free chloride concentration profiles were measured every two hours using the NMR technique.

The parameter identification process in the drying problem is more difficult than in the wetting experiment. The storage parameters can be measured using basically the same methods as in the wetting process, only the initial conditions are different because desorption is taking place during drying. However, the determination of transport parameters cannot be done in a similar way as in the case of wetting. The main problem is with the boundary conditions in the drying process where contrary to the wetting process the Newton conditions are to be used. This leads to a necessity to identify another unknown parameter, which is the moisture transfer coefficient between the specimen surface and the surroundings. If the moisture diffusivity and salt diffusion coefficient in the drying phase could be considered the same as in the wetting phase, than the fitting procedure to find the moisture transfer coefficient might be relatively easy although this parameter is supposedly a function of moisture content. Unfortunately, both moisture diffusivity and salt diffusion coefficient appear to depend on the orientation of the process similarly as the moisture and salt storage parameters. As a consequence, for the determination of three unknown parameters (which, in addition, are the functions of field variables of an 
unknown type) we have only two sets of measured profiles. In such a case the solution of the inverse problem can only be roughly estimated using a computational fitting procedure and this estimate cannot be considered as a unique solution. Nevertheless, even this rough estimate can be useful for an improvement of the accuracy of computer simulated data in the coupled water and salt transport process.

\section{Computational results}

In the computational simulations, moisture diffusivity, chloride diffusion coefficient and moisture transfer coefficient were the free parameters which were supposed to be fitted according to the experimental data. The least square method was used for the assessment of simulated data in the particular cases.

Fig. 1 shows a comparison of moisture transfer coefficients $\alpha$ calculated for the process of drying of limestone saturated with $3-\mathrm{M} \mathrm{NaCl}$ solution with and without inhibitor. The presence of inhibitor in the solution has led to a significant decrease of moisture transfer coefficient, in certain moisture ranges even to almost one half when compared to the solution without inhibitor. In other words, the inhibitor caused the evaporation rate from the specimen surface to decrease.

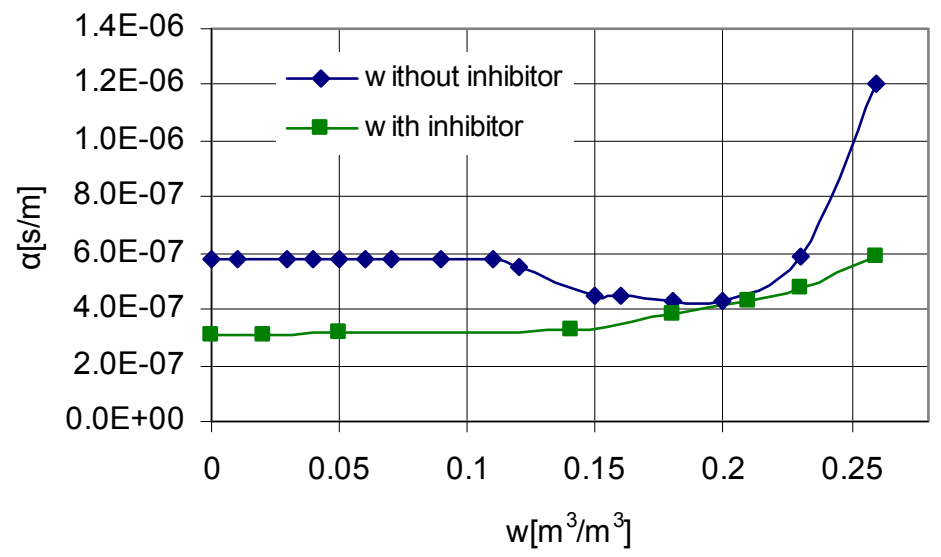

Figure 1: Final moisture transfer coefficient.

Fig. 2 gives evidence that liquid moisture transport in limestone was slowed down quite remarkably when inhibitor was added to the $\mathrm{NaCl}$ solution. The differences in moisture diffusivity were as high as one to two orders of magnitude. This seems to be a surprising result. Taking into account that the porous matrix should be basically unaffected by the presence of inhibitor which is not supposed to react with it or to promote its chemical reaction with $\mathrm{NaCl}$, the most probable reason for the decrease of moisture diffusivity was an increase in viscosity of the solution. However, this is not an expected behaviour of crystallization inhibitor in salt solution. 


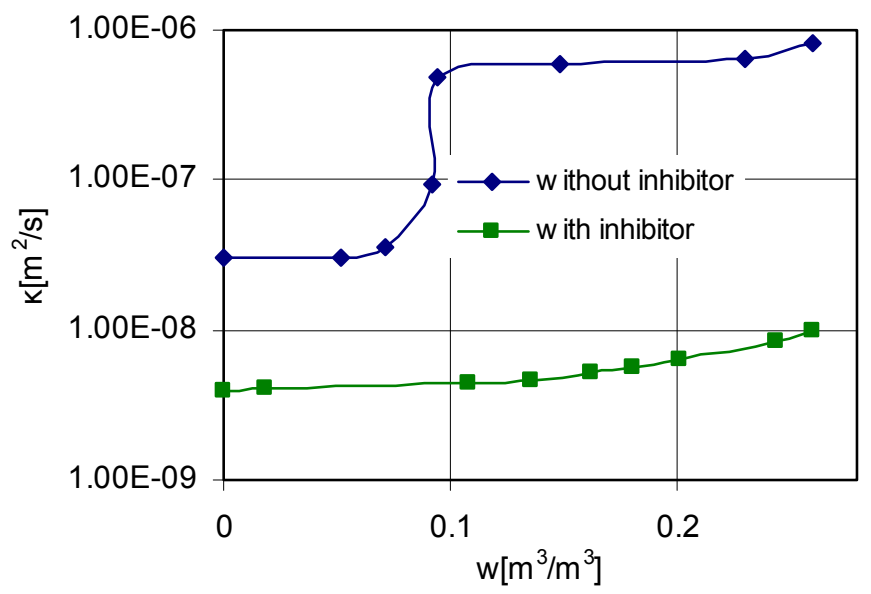

Figure 2: Final moisture diffusivity.

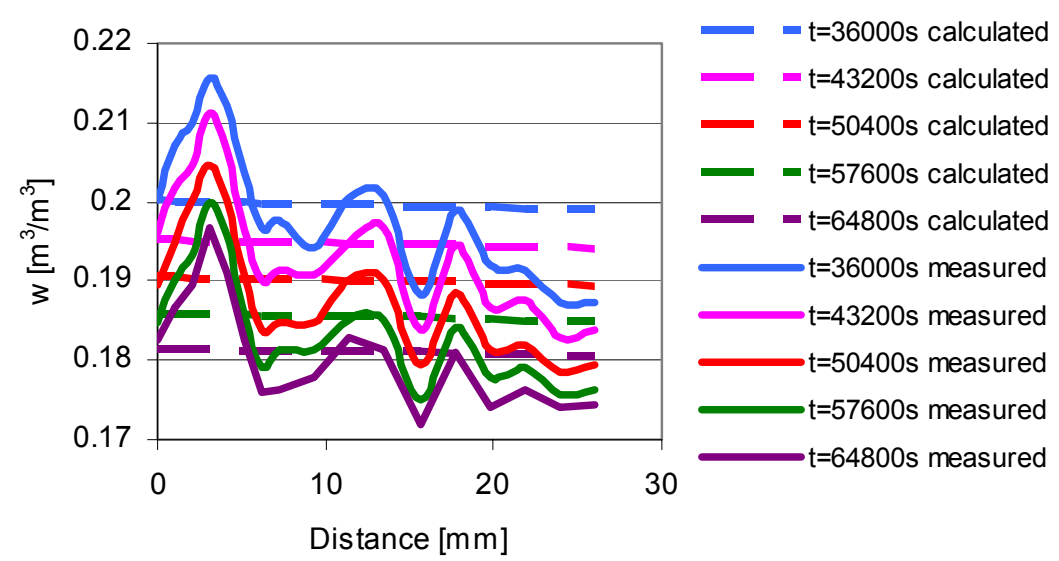

Figure 3: Comparison of calculated and experimental moisture profiles for drying of limestone saturated with $3-\mathrm{M} \mathrm{NaCl}$ solution without inhibitor.

Figs. 3 and 4 present examples of the comparison of calculated and experimental moisture profiles for drying of limestone saturated with $3-\mathrm{M} \mathrm{NaCl}$ solution with and without inhibitor. The differences between computational and measured data are for both experiments clearly in reasonable limits, taking into account the irregularities in the material which are well visible on experimental curves.

Fig. 5 shows that the chloride binding capacity of limestone decreased due to the presence of inhibitor over almost whole the range of free chloride 
concentrations. However, the differences in the amounts of bound chlorides were not very high, only $5 \%$ in maximum, so that the trend could not be evidenced definitely.

The chloride diffusion coefficient in limestone was affected by the crystallization inhibitor in a significant way only in the range of lower concentrations (typically, up to $170 \mathrm{kgm}^{-3}$ ) where it decreased by one to two orders of magnitude as it is documented in Fig. 6. This may be related to an increased viscosity of the solution, or, possibly, also to a decreased interface tension on the pore walls.

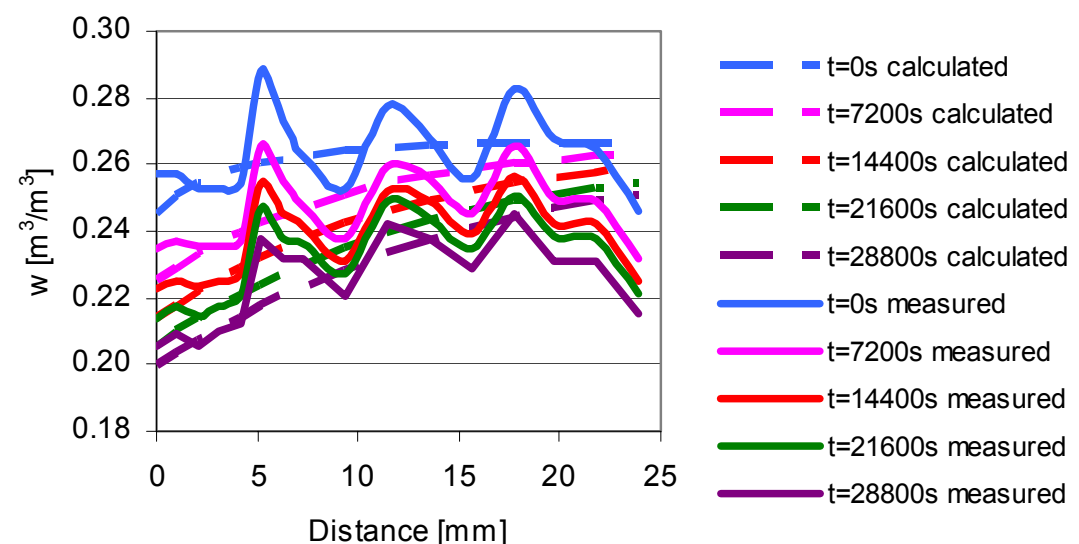

Figure 4: Comparison of calculated and experimental moisture profiles for drying of limestone saturated with $3-\mathrm{M} \mathrm{NaCl}$ solution with inhibitor.

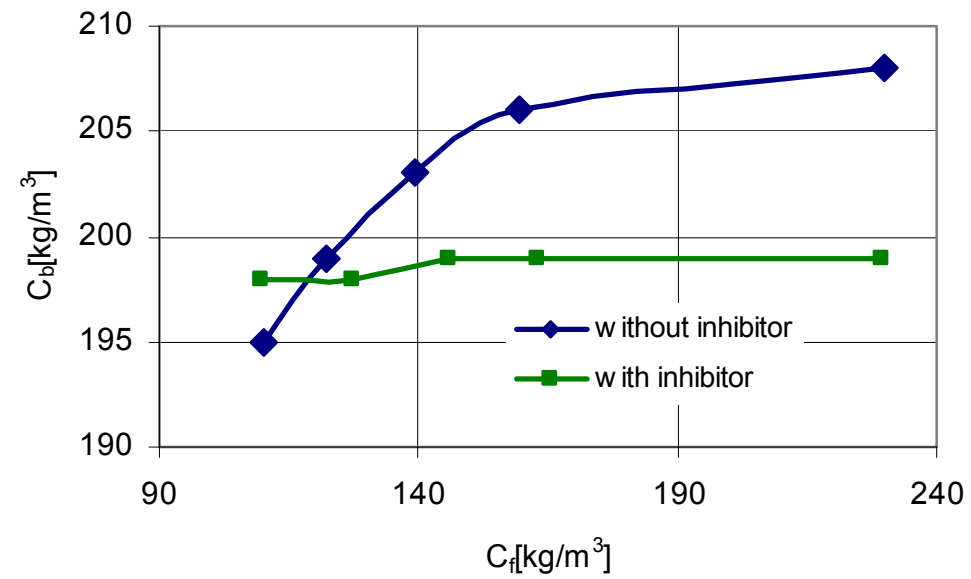

Figure 5: Final chloride binding isotherms. 


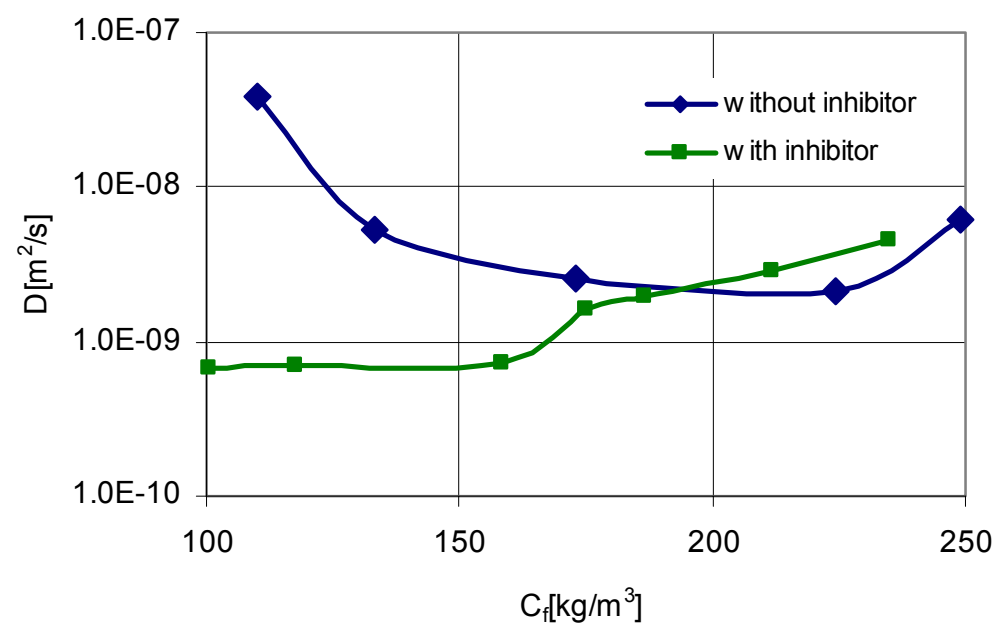

Figure 6: Final chloride diffusion coefficients.

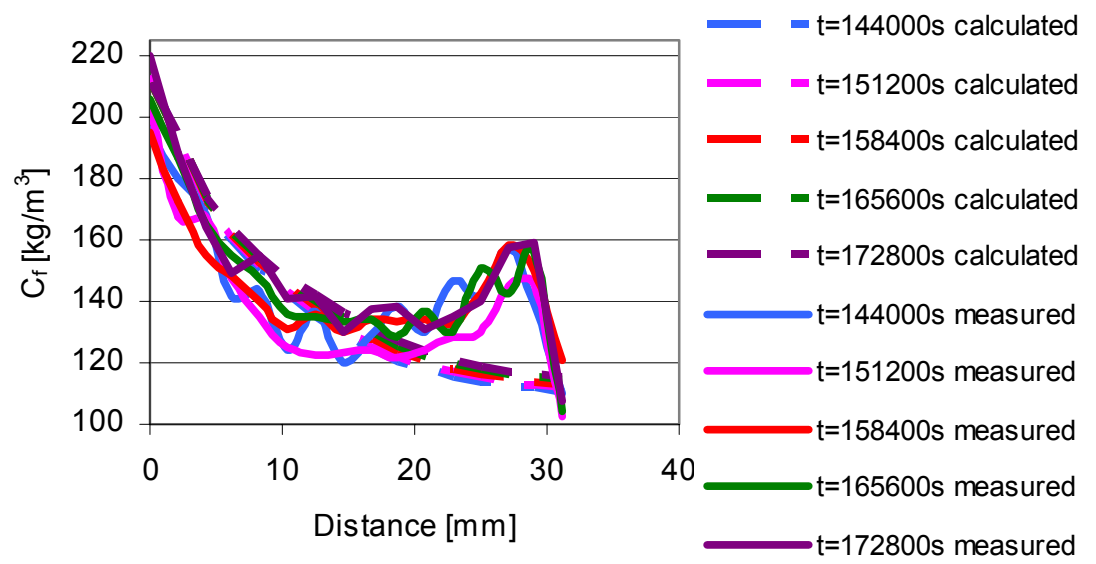

Figure 7: Comparison of calculated and experimental free $\mathrm{NaCl}$ concentration profiles for drying of limestone saturated with 3-M $\mathrm{NaCl}$ solution without inhibitor.

Figs. 7 and 8 present examples of the comparison of calculated and experimental free chloride concentration profiles for $\mathrm{NaCl}$ solutions with and without inhibitor. Similarly as with the moisture profiles, the differences between measured and computer simulated data were within reasonable limits so that the model could be considered as applicable for the prediction of moisture and salt concentration profiles. 


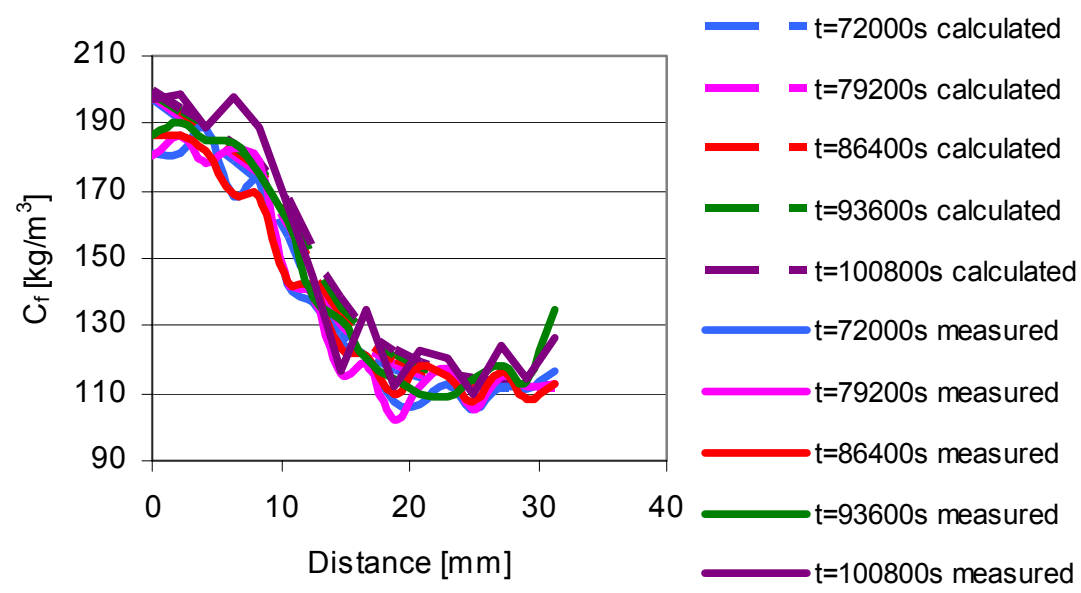

Figure 8: Comparison of calculated and experimental free $\mathrm{NaCl}$ concentration profiles for drying of limestone saturated with 3-M $\mathrm{NaCl}$ solution with inhibitor.

\section{Conclusions}

Computational simulations of coupled water and salt transport in this paper have shown that in the process of drying of limestone saturated with $3-\mathrm{M} \mathrm{NaCl}$ solution both water transport and chloride transport were slowed down due to the addition of $\left.0.001-\mathrm{M} \mathrm{Na} \mathrm{Na}_{4} \mathrm{FeN}\right)_{6} \cdot 10 \mathrm{H}_{2} \mathrm{O}$ as crystallization inhibitor. The explanation of this finding may lie in the increase of viscosity of the chloride solution and/or decrease of interface tension on the pore walls. This statement is, however, just a hypothesis at the moment which should be verified by further experimental work.

\section{Acknowledgement}

This research was supported by Czech Science Foundation, under grant No. 103/06/0031.

\section{References}

[1] Carslaw H.S., Jaeger J.C. Conduction of Heat in Solids. Clarendon Press, Oxford, 1959.

[2] Matano, C. On the relation between the diffusion coefficient and concentration of solids metals. Jap. J. Phys. 8, pp.109-115, 1933.

[3] Bear, J., Bachmat, Y. Introduction to Modeling of Transport Phenomena in Porous Media. Vol. 4, Kluwer, Dordrecht 1990. 
[4] Pel L., Kopinga K., Kaasschieter E. F. Saline absorption in calciumsilicate brick observed by NMR scanning. J. Phys. D: Appl. Phys, 33, 1380-1385, 2000.

[5] Pel L., Černý R., Pavlík Z. Moisture and Ion Transport. WP5 2-Years Report of the EU 6 ${ }^{\text {th }}$ Program Project SSPI-CT-2003-501571. TU Eindhoven, Eindhoven 2006. 